\title{
A supply chain model under return policy considering refurbishment, learning effect and inspection error
}

\author{
Sujata Saha ${ }^{1, *}$ and Tripti Chakrabarti ${ }^{2}$ \\ 1 Mankar College, Mankar, 713144 West Bengal, India \\ E-mail:〈sahasujata@outlook.com〉 \\ 2 Techno India University, Kolkata, 700091 West Bengal, India \\ E-mail: 〈triptichakrabarti@gmail.com〉
}

\begin{abstract}
This article presents a three-echelon supply chain model consisting of a supplier, manufacturer, and a retailer, considering the return contract between the manufacturer and the retailer. Here, the manufacturer has two adjacent production units - the main production unit and a refurbishment unit. The main production unit of the manufacturer is imperfect, which produces an admixture of perfect and defective items. He inspects all the products immediately after production and sells good quality items to the retailer. The retailer receives a proportion of faulty products from him due to his erroneous inspection process, which he returns after inspection. The manufacturer sends all the defective products received from the retailer and the main production unit to the refurbishment unit for reworking. Moreover, the learning effect of the employees on the production cost is considered. Under these circumstances, the cost functions of each of the supply chain players have been derived. Finally, the applicability of the proposed model has been shown using a numerical example. The sensitivity analysis has been presented to study the effect of the parameters on the optimum decision variables.
\end{abstract}

Keywords: imperfect production, inspection error, learning effect, refurbishment, return policy, threeechelon

Received: October 10, 2019; accepted: June 14, 2020; available online: July 07, 2020

DOI: $10.17535 /$ crorr.2020.0005

\section{Introduction}

In practice, almost every production system faces some inherent problems associated with the production system such as machinery fault, defective raw materials, lethargy of the production system for continuous work etc. As a natural consequence, when production is going on in the factory, it is seen that some quantity of items produced is of imperfect quality. Therefore, researchers in this era have considered the effect of imperfect production while developing supply chain production inventory models. [13] was among the first study, which considered the imperfect production while developing their model. In this model, they assumed that the system deteriorates in the production runtime when it produces a certain percentage of defective products with the good quality products. They showed that the optimum production cycle in this model is shorter than that of the traditional economic production quantity model. [7] extended the economic production lot size model considering that the performance of the production process deteriorates significantly with the increase in the production rate. In the later time, this model was extended by [14], incorporating the idea that the production system is in the in-control state at the beginning of the production process, where it produces all the perfect

${ }^{*}$ Corresponding author.

http://www.hdoi.hr/crorr-journal

(C)2020 Croatian Operational Research Society 
quality items. The production system shifts from the in-control state to an out-of-control state due to higher production rate and production runtime, when it produces a fraction of imperfect quality items with the perfect items. [8] developed a lot-size model where the production process has the probability to reach an out-of-control state and produce imperfect quality items. In this model, they assumed that the imperfect items are not defective and therefore they are removed from the inventory to be used elsewhere. The article on the imperfect production system by [14] was further extended by [16] considering the dependence of the selling price on the production cost and the screening cost of the items. Again, in the reality, it is observed that the supply chain players commit mistakes frequently while screening the products. Some perfect items are mistakenly sorted as imperfect, while a proportion of imperfect items are sorted as perfect when they inspect the products. Researchers have developed the supply chain models considering the erroneous inspection process $[4,5,17]$. Apart from the inspection error, another important factor observed in the production system is the gradual decrease in the production cost, which happens due to the learning effect of the employees. Because of the gaining adeptness of the employees with time, the wastage of raw materials or the other resources necessary for the production decreases gradually with time. Furthermore, as they became accustomed to the working environment, they are being capable of doing more work than the previous in the same time period. Due to these reasons, the production cost decreases over time. A numerous researcher has developed supply chain models taking into account the learning effect of the employees $[1,2,6,9,12,15]$. The customers are an integral part of any business, and the revenue of any business depends solely on them. So, the vendors always try to entice them by offering some coordination policy, such as the return policy. Under this policy, the buyers can return the defective products to the vendors which makes an economic sense to the buyers and are encouraged to buy more products from them [10]. [11] developed a two-echelon inventory model considering both manufacturing and the remanufacturing processes with product return. They assumed that the returned products are transformed into a serviceable one by the remanufacturing process. In this model, it has shown that as the remanufacturing cost is less than the cost of producing new items, it leads to a decrease in the supply chain cost. [18] represented a pricing model consisting of a single supplier and multiple retailers, considering the return policy, which suggested that the inventory competition can achieve a stable solution when the enterprise adopts the buy-back policy with the pricing and the return policy.

Best known to the authors of this paper, no study previously considered the gradual decrease in the production cost due to the learning effect of the employees, which is a genuine issue observed in the production firm. As employees become skilful with time, the wastage of raw materials or the other resources necessary for the production decreases gradually. Furthermore, as they became accustomed to the working environment, they are being capable of doing more work than the previous in the same period. Due to these reasons, the production cost decreases over time. Moreover, no study examined the ordering and production decisions in a threeechelon supply chain model considering the refurbishment of the defective products produced during the production period as well as those returned from the buyer. Furthermore, despite the importance of the refurbishment work, the role of the refurbishment unit of the manufacturer is poorly studied. Therefore, this paper aims to address these issues.

In this model, we have developed a three-echelon supply chain model in an imperfect production system comprising single supplier, single manufacturer and a single retailer. The manufacturer has two adjacent production units - the main production unit and a refurbishment unit. He receives raw materials from the supplier and transforms these into the finished products. As the manufacturing system is imperfect, it produces a fraction of defective products with the perfect products. The manufacturer inspects all the products immediately after production and sells the perfect quality products to the retailer. Due to the erroneous inspection process of the manufacturer, the retailer receives a fraction of defective products with the perfect products. The manufacturer offers a return policy to the retailer so that he can return all the defective 
products to the manufacturer. The manufacturer collects all the defective products from the main production unit as well as from the retailer and sends these to the refurbishment unit. The refurbishment unit makes all these defective products serviceable by some refurbishment work, check its functionality and the defects, and then sells these to the customers at a reduced price. Finally, the cost functions of each of the supply chain players, as well as the cost function of the whole supply chain system, have been derived. We have solved this proposed model by the Leader-Follower relationship approach.

\section{Notations and assumptions}

\subsection{Notations}

We have used the following notations to develop the model:

- $I_{1 m}(t)$ : the inventory level at time t of the manufacturer (in the main production unit),

- $I_{2 m}(t)$ : the inventory level at time $\mathrm{t}$ of the manufacturer (in the refurbishment unit),

- $I_{1 r}(t)$ : the inventory level at time $t$ of the retailer,

- $Q$ : the lot size of the supplier,

- $D_{m}$ : the demand rate of the manufacturer to the supplier,

- $D_{c}$ : the demand rate of the customer to the retailer, which is dependent on the selling price of the retailer, i.e. $D_{c}=a-b S_{r}$, where a is the deterministic part of market demand, $a>0$ and $b$ is the price sensitivity parameter $b>0$.

- $D_{c}^{\prime}$ : the demand rate of the customers for the refurbished products to the manufacturer,

- $D_{r}$ : the demand rate of the retailer to the manufacturer,

- $p_{m}$ : the production rate of the manufacturer,

- $A_{s}$ : the ordering cost of the supplier,

- $A_{m}$ : the set-up cost of the manufacturer for the main production unit,

- $A_{m}^{\prime}$ : the set-up cost of the manufacturer for the refurbishment unit,

- $A_{r}$ : the ordering cost of the retailer,

- $h_{s}$ : the holding cost per unit item per unit time of the supplier,

- $h_{m}$ : the holding cost per unit perfect item per unit time of the manufacturer (in the main production unit),

- $h_{m}^{\prime}$ : the holding cost per unit imperfect item per unit time of the manufacturer (in the refurbishment unit),

- $h_{r}$ : the holding cost per unit item per unit time of the retailer,

- $P_{s}$ : the purchasing cost per unit of the raw materials of the supplier,

- $P_{s}^{\prime}$ : the salvage value per unit of the defective raw materials of the supplier,

- $C_{s}$ : inspection cost per unit raw material of the supplier,

- $C_{m}$ : inspection cost per unit item of the manufacturer, 
- $C_{r}$ : inspection cost per unit item of the retailer,

- $y$ : the percentage of non-conforming raw materials received by the supplier,

- $z$ : the percentage of defective products produced by the manufacturer in the main production unit,

- $x$ : the percentage of defective products received by the retailer,

- $C_{p}$ : production cost per unit item of the manufacturer,

- $f_{c}$ : refurbishment cost per unit defective items of the manufacturer,

- $S_{m}$ : selling price per unit item of the manufacturer, i.e. purchasing cost per unit item of the retailer

- $S_{r}$ : selling price per unit item of the retailer.

\subsection{Assumptions}

We have assumed the following to develop the model:

1. The manufacturer's demand rate for raw material to the supplier is higher than the production rate of the items, to get rid of the shortage of raw materials in the production period, i.e., $D_{m} \geq p_{m}$.

2. Due to the learning effect of the employees, the production cost of the manufacturer decreases gradually with time. Here we have assumed the production cost as

$$
C_{p}=\left(\alpha+e^{-\beta t}\right),
$$

where $\alpha, \beta>0$ are constants and $\beta$ id the learning parameter.

\section{Mathematical model}

In this section, we have formulated the models for the supplier, manufacturer, and the retailer. A pictorial representation of this supply chain system has been depicted in the Figure 1.

\subsection{Supplier's model}

The supplier procures raw materials from an outside supplier in a lot size $Q$. He screens all the raw materials immediately after receiving these and supplies the good quality raw materials to the manufacturer. Let the fraction of defective items observed by the supplier is $y$. The amount of perfect quality raw materials is $(1-y) Q$. The supplier sells all the raw materials to the manufacturer at a rate $D_{m}$ during $\left(0, t_{1}\right)$. Therefore,

$$
t_{1}=\frac{(1-y) Q}{D_{m}} .
$$

Holding cost of the raw materials is

$$
h_{s}\left\{\frac{1}{2}(1-y) Q t_{1}\right\}=\frac{h_{s}\{(1-y) Q\}^{2}}{2 D_{m}} .
$$

Therefore, total cost of the supplier $=($ Ordering cost + Purchasing cost + Inspection cost + The salvage value of the non-conforming raw materials + Holding cost), i.e.

$$
T C_{s}=A_{s}+\left(P_{s}+C_{s}-P_{s}^{\prime} y\right) Q+\frac{h_{s}\{(1-y) Q\}^{2}}{2 D_{m}} .
$$




\subsection{Manufacturer's model}

\section{Mathematical model for the main production unit}

The manufacturer starts producing the items at a rate $p_{m}$ at time $t=0$ and continues up to time $t=t_{1}$. The inventory level depletes due to retailer's demand and reaches to the zero level at time $t=t_{3}$. The following differential equations describe the rate of change of inventory level for the perfect quality items of the manufacturer

$$
\frac{d I_{1 m}(t)}{d t}= \begin{cases}(1-z) p_{m}-D_{r}, & 0 \leq t \leq t_{1} \\ -D_{r}, & t_{1} \leq t \leq t_{3}\end{cases}
$$

with

Solving (3) we get

$$
I_{1 m}(0)=0, I_{1 m\left(t_{3}\right)=0}
$$

$$
I_{1 m}(t)= \begin{cases}\left\{(1-z) p_{m}-D_{r}\right\} t & 0 \leq t \leq t_{1} \\ -D_{r}\left(t-t_{3}\right), & t_{1} \leq t \leq t_{3}\end{cases}
$$

From the continuity condition of $I_{1 m}(t)$ at $t=t_{1} 1$ we have

$$
\left\{(1-z) p_{m}-D_{r}\right\} t_{1}=-D_{r}\left(t_{1}-t_{3}\right),
$$

i.e.,

$$
t_{3}=\frac{(1-z) p_{m} t_{1}}{D_{r}}=\frac{(1-y)(1-z) p_{m} Q}{D_{m} D_{r}} .
$$

Now, set up cost of the manufacturer:

$$
A_{m}
$$

$$
\begin{aligned}
\int_{0}^{t_{1}} p_{m} C_{p} d t & =p_{m} \int_{o}^{t_{1}}\left(\alpha+e^{-\beta t}\right) d t=p_{m}\left\{\alpha t_{1}-\frac{1}{\beta}\left(e^{-\beta t_{1}}-1\right)\right\} \\
& =p_{m}\left\{\frac{\alpha(1-y) Q}{D_{m}}-\frac{1}{\beta}\left(e^{-\frac{\beta(1-y) Q}{D_{m}}}-1\right)\right\} .
\end{aligned}
$$

Inspection cost:

$$
\frac{C_{m} p_{m}(1-y) Q}{D_{m}}
$$

Holding cost for perfect quality items:

$$
\begin{aligned}
h_{m}\left[\int_{0}^{t_{1}} I_{1 m}(t) d t+\int_{t_{1}}^{t_{3}} I_{1 m}(t) d t\right] & =h_{m}\left[\int_{0}^{t_{1}}\left\{(1-z) p_{m}-D_{r}\right\} t d t-\int_{t_{1}}^{t_{3}} D_{r}\left(t-t_{3}\right) d t\right] \\
& =\frac{h_{m}}{2}\left\{\left\{(1-z) p_{m}-D_{r}\right\} t_{1}^{2}+D_{r}\left(t_{1}-t_{3}\right)^{2}\right\} \\
& =\frac{h_{m}}{2}\left\{\left\{(1-z) p_{m}-D_{r}\right\} t_{1}^{2}+\frac{\left\{(1-z) p_{m}-D_{r}\right\}^{2} t_{1}^{2}}{D_{r}}\right\} \\
& =\frac{h_{m}}{2} \cdot \frac{\left\{(1-z) p_{m}-D_{r}\right\}(1-z)(1-y)^{2} p_{m} Q^{2}}{D_{m}^{2} D_{r}} .
\end{aligned}
$$

Therefore, the total cost of the manufacturer in the main production unit:

$$
\begin{aligned}
T C_{1 m}=A_{m} & +p_{m}\left\{\frac{\alpha(1-y) Q}{D_{m}}-\frac{1}{\beta}\left(e^{-\frac{\beta(1-y) Q}{D_{m}}}-1\right)\right\}+ \\
& +\frac{C_{m} p_{m}(1-y) Q}{D_{m}}+\frac{h_{m}}{2} \cdot \frac{\left\{(1-z) p_{m}-D_{r}\right\}(1-z)(1-y)^{2} p_{m} Q^{2}}{D_{m}^{2} D_{r}}
\end{aligned}
$$




\section{Mathematical model for the refurbishment unit}

The manufacturer collects all the defective products from the main production unit as well as from the retailer and sends these to the refurbishment unit. The refurbishment unit makes all these defective products usable and sells these directly to the customers at a rate $D_{c}^{\prime}$. The following differential equations describe the rate of change of the inventory level:

$$
\frac{d I_{2 m}(t)}{d t}=\left\{\begin{array}{lr}
\left(z p_{m}+x D_{r}\right)-D_{c}^{\prime}, & 0 \leq t \leq t_{1} \\
x D_{r}-D_{c}^{\prime}, & t_{1} \leq t \leq t_{3} \\
-D_{c}^{\prime}, & t_{3} \leq t \leq t_{m}
\end{array}\right.
$$

with boundary conditions $I_{2 m}(0)=0, I_{2 m}\left(t_{1}\right)=\left(z p_{m}+x D_{r}-D_{c}^{\prime}\right) t_{1}, I_{2 m}\left(t_{m}\right)=0$. Solving $(7)$ we have:

$$
I_{2 m}(t)=\left\{\begin{array}{lr}
\left(z p_{m}+x D_{r}-D_{c}^{\prime}\right) t, & 0 \leq t \leq t_{1} \\
\left(x D_{r}-D_{c}^{\prime}\right) t+z p_{m} t_{1}, & t_{1} \leq t \leq t_{3} \\
-D_{c}^{\prime}\left(t-t_{m}\right), & t_{3} \leq t \leq t_{m}
\end{array}\right.
$$

From the continuity condition of $I_{2 m}(t)$ at $t=t_{3}$ we have:

$$
\left(x D_{r}-D_{c}^{\prime}\right) t+z p_{m} t_{1}=-D_{c}^{\prime}\left(t-t_{m}\right)
$$

i.e.,

$$
t_{m}=\frac{x D_{r} t_{3}+z p_{m} t_{1}}{D_{c}^{\prime}}=\frac{\{x(1-z)+z\}(1-y) Q p_{m}}{D_{m} D_{r}} .
$$

Set up cost:

$$
A_{m}^{\prime}
$$

Cost of refurbishment:

$$
=f_{c} D_{c}^{\prime} t_{3}=\frac{f_{c} D_{c}^{\prime}(1-y)(1-z) p_{m} Q}{D_{m} D_{r}} .
$$

Holding cost:

$$
\begin{aligned}
& =h_{m}^{\prime}\left[\int_{0}^{t_{1}} I_{2 m}(t) d t+\int_{t_{1}}^{t_{3}} I_{2 m}(t)+\int_{t_{3}}^{t_{m}} I_{2 m}(t) d t\right] \\
& =h_{m}^{\prime}\left[\int_{0}^{t_{1}}\left(z p_{m}+x D_{r}-D_{c}^{\prime}\right) t d t+\int_{t_{1}}^{t_{3}}\left\{\left(x D_{r}-D_{c}^{\prime}\right) t+z p_{m} t_{1}\right\} d t-\int_{t_{3}}^{t_{m}} D_{c}^{\prime}\left(t-t_{m}\right) d t\right] \\
& =\frac{h_{m}^{\prime}}{2}\left[\left(z p_{m}+x D_{r}-D_{c}^{\prime}\right) t_{1}^{2}+\left(x D_{r}-D_{c}^{\prime}\right)\left(t_{3}^{2}-t_{1}^{2}\right)+2 z p_{m} t_{1}\left(t_{3}-t_{1}\right)+D_{c}^{\prime}\left(t_{3}-t_{m}\right)^{2}\right] .
\end{aligned}
$$

Putting the values of $t_{1}, t_{3}$ and $t_{m}$ from the equations (1), (5), and (9) respectively and simplifying we have the holding cost of the manufacturer in the refurbishment unit as:

$$
\begin{aligned}
\frac{h_{m}^{\prime}}{2}\left[z p _ { m } \left\{\frac{2(1-z) p_{m}}{D_{r}}\right.\right. & -1\} \frac{(1-y)^{2} Q^{2}}{D_{m}^{2}}+\frac{\left(x D_{r}-D_{c}^{\prime}\right)(1-y)^{2}(1-z)^{2} p_{m}^{2} Q^{2}}{D_{m}^{2} D_{r}^{2}} \\
& \left.+D_{c}^{\prime}\left\{\frac{(1-z)}{D_{r}}-\frac{x(1-z)+z}{D_{c}^{\prime}}\right\}^{2} \frac{(1-y)^{2} p_{m}^{2} Q^{2}}{D_{m}^{2}}\right] .
\end{aligned}
$$


Therefore, the total cost of the manufacturer in the refurbishment unit:

$$
\begin{aligned}
T C_{2 m} & =A_{m}^{\prime}+\frac{f_{c} D_{c}^{\prime}(1-y)(1-z) p_{m} Q}{D_{m} D_{r}}+ \\
& +\frac{h_{m}^{\prime}}{2}\left\{z p_{m}\left(\frac{2(1-z) p_{m}}{D_{r}}-1\right) \frac{(1-y)^{2} Q^{2}}{D_{m}^{2}}+\frac{\left(x D_{r}-D_{c}^{\prime}\right)(1-y)^{2}(1-z)^{2} p_{m}^{2} Q^{2}}{D_{m}^{2} D_{r}^{2}}\right. \\
& \left.+D_{c}^{\prime}\left(\frac{(1-z)}{D_{r}}-\frac{x(1-z)+z}{D_{c}^{\prime}}\right)^{2} \frac{(1-y)^{2} p_{m}^{2} Q^{2}}{D_{m}^{2}}\right\} .
\end{aligned}
$$

Therefore, total cost of the manufacturer:

$$
\begin{aligned}
T C_{m} & =T C_{1 m}+T C_{2 m}=A_{m}+A_{m}^{\prime}+p_{m}\left\{\frac{\alpha(1-y) Q}{D_{m}}-\frac{1}{\beta}\left(e^{-\frac{\beta(1-y) Q}{D_{m}}}-1\right)\right\} \\
& +\frac{C_{m} p_{m}(1-y) Q}{D_{m}}+\frac{f_{c} D_{c}^{\prime}(1-y)(1-z) p_{m} Q}{D_{m} D_{r}} \\
& +\frac{h_{m}}{2} \cdot \frac{\left\{(1-z) p_{m}-D_{r}\right\}(1-z)(1-y)^{2} p_{m} Q^{2}}{D_{m}^{2} D_{r}} \\
& +\frac{h_{m}^{\prime}}{2}\left\{z p_{m}\left(\frac{2(1-z) p_{m}}{D_{r}}-1\right) \frac{(1-y)^{2} Q^{2}}{D_{m}^{2}}+\frac{\left(x D_{r}-D_{c}^{\prime}\right)(1-y)^{2}(1-z)^{2} p_{m}^{2} Q^{2}}{D_{m}^{2} D_{r}^{2}}\right. \\
& \left.+D_{c}^{\prime}\left(\frac{(1-z)}{D_{r}}-\frac{x(1-z)+z}{D_{c}^{\prime}}\right)^{2} \frac{(1-y)^{2} p_{m}^{2} Q^{2}}{D_{m}^{2}}\right\} .
\end{aligned}
$$

\subsection{Retailer's model}

He starts purchasing the items at time $t=0$ and continues up to time $t=t_{3}$. The level of the retailer's inventory depletes due to the customers' demand and reaches to the zero level at time $t=T$. The following differential equations describe the rate of change of the inventory level:

$$
\frac{d I_{1 r}(t)}{d t}= \begin{cases}(1-x) D_{r}-D_{c}, & 0 \leq t \leq t_{3} \\ -D_{c}, & t_{3} \leq t \leq T\end{cases}
$$

with

$$
I_{1 r}(0)=0, I_{1 r}(T)=0 .
$$

Solving equation (11) we have:

$$
\frac{d I_{1 r}(t)}{d t}=\left\{\begin{array}{lr}
\left\{(1-x) D_{r}-D_{c}\right\} t, & 0 \leq t \leq t_{3} \\
-D_{c}(t-T), & t_{3} \leq t \leq T
\end{array}\right.
$$

From the continuity condition of $I_{1 r}(t)$ at $t=t_{3}$ we have:

$$
\left\{(1-x) D_{r}-D_{c}\right\} t_{3}=-D_{c}\left(t_{3}-T\right),
$$

i.e.,

$$
T=\frac{(1-x) D_{r}}{D_{c}} t_{3}=\frac{(1-x)(1-y)(1-z) p_{m} Q}{D_{m} D_{c}}
$$

Ordering cost of the retailer:

$$
=A_{r}
$$


Purchasing cost:

$$
=S_{m}(1-x) D_{r} t_{3}=\frac{s_{m}(1-x)(1-y)(1-z) p_{m} Q}{D_{m}} .
$$

Inspection cost:

$$
=C_{r} D_{r} t_{3}=\frac{c_{r}(1-y)(1-z) p_{m} Q}{D_{m}} .
$$

Holding cost:

$$
\begin{aligned}
& =h_{r}\left[\int_{0}^{t_{3}} I_{1 r}(t) d t+\int_{t_{3}}^{T} I_{1 r}(t) d t\right] \\
& =h_{r}\left[\int_{0}^{t_{3}}\left\{(1-x) D_{r}-D_{c}\right\} t d t-\int_{t_{3}}^{T} D_{c}(t-T)(t) d t\right] \\
& =\frac{h_{r}}{2}\left[\left\{(1-x) D_{r}-D_{c}\right\} t_{3}^{2}+D_{c}\left(t_{3}-T\right)^{2}\right] \\
& =h_{r} \frac{(1-x)(1-y)^{2}(1-z)^{2}\left\{(1-x) D_{r}-D_{c}\right\} P_{m}^{2} Q^{2}}{2 D_{m}^{2} D_{r} D_{c}} .
\end{aligned}
$$

Therefore, total cost of the retailer per unit time:

$$
\begin{aligned}
T C_{r}=A_{r} & +\frac{C_{r}(1-y)(1-z) p_{m} Q}{D_{m}}+\frac{S_{m}(1-x)(1-y)(1-z) p_{m} Q}{D_{m}} \\
& +h_{r} \frac{(1-x)(1-y)^{2}(1-z)^{2}\left\{(1-x) D_{r}-D_{c}\right\} P_{m}^{2} Q^{2}}{2 D_{m}^{2} D_{r} D_{c}}
\end{aligned}
$$

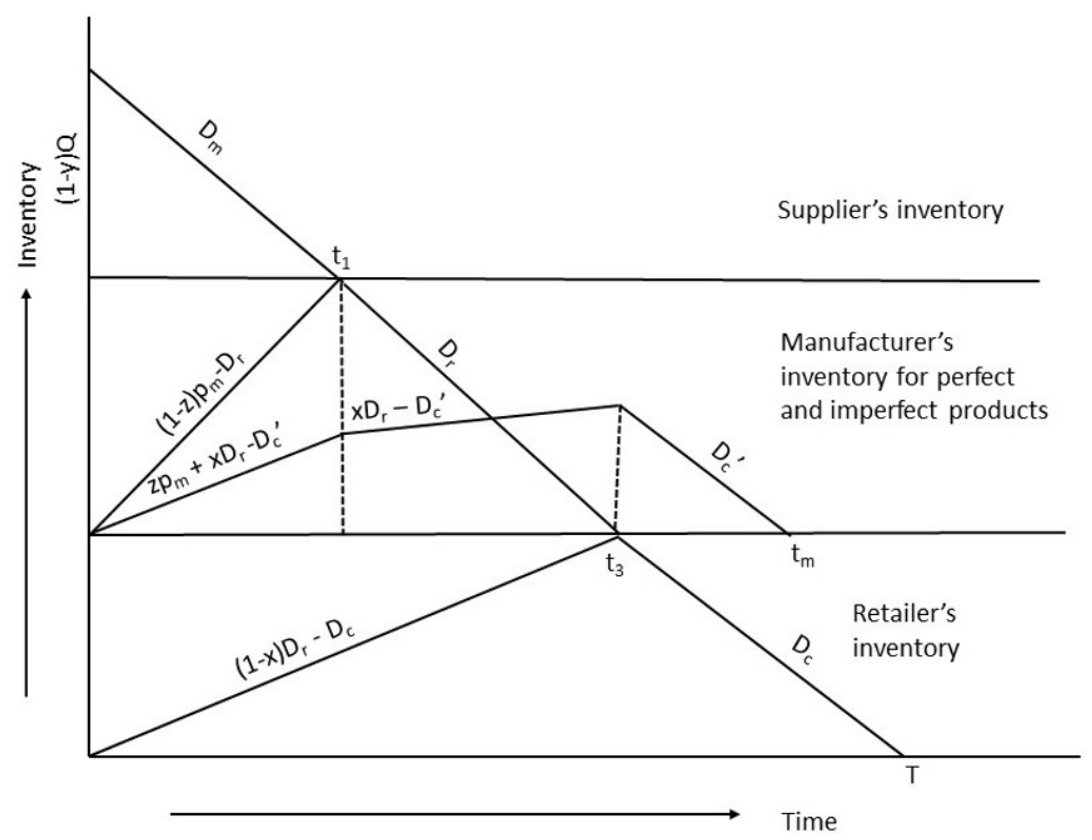

Figure 1: Pictorial representation of the model 


\section{Solution method}

\section{Leader-follower relationship}

The members of competing supply chains do not always take their decision simultaneously and in the reality, we confront with the leader-follower relationship in many cases. Under this theory, the leaders and the followers maintain a relationship through negotiation to decide what each party is willing to exchange [3]. In this model, the supplier is to invest in inspecting the raw materials as he supplies only good quality raw materials. Therefore, we consider the supplier as the manufacturer's leader. Again, under the return contract offered by the manufacturer, the retailer can return the defective products to him. For providing such facility, we consider the manufacturer as the retailer's leader. First, the supplier decides on his decision variable by optimizing his own cost. Then the manufacturer determines his decision variable and optimizes his total cost using the supplier's optimum decision variable. Finally, the retailer's total cost is obtained depending on the optimum values of the supplier and the manufacturer's decision variables. Therefore, here the manufacturer follows the supplier and the retailer follows both the supplier and the manufacturer.

In this model, the supplier provides only the good quality raw materials to the manufacturer and to do so he is to invest on inspecting the materials. Again, the manufacturer offers a return policy to the retailer so that he can return the defective products to him. Due to these facts we consider the supplier and the manufacturer as the leaders and the retailer as the follower. Here, $Q$ is the supplier's decision variable. As in this case, the supplier decides on his own decision variable independently, the total cost of the supplier per unit time is

$$
T C_{s l}=\frac{1}{t_{1}}\left(T C_{s}\right)=\frac{A_{s} D_{m}}{(1-y) Q}+\frac{\left(P_{s}+C_{s}-P_{s}^{\prime} y\right) D_{m}}{(1-y)}+\frac{h_{s}(1-y) Q}{2} .
$$

Now, differentiating the supplier's cost function $T C_{s l}$ with respect to $Q$ we have:

$$
\frac{\partial\left(T C_{s l}\right)}{\partial Q}=-\frac{D_{m} A_{s}}{Q^{2}(1-y)}+\frac{h_{s}(1-y)}{2},
$$

and

$$
\frac{\partial^{2}\left(T C_{s l}\right)}{\partial Q^{2}}=\frac{2 D_{m} A_{s}}{Q^{3}(1-y)}>0 .
$$

This proves that the supplier's cost function is convex. Therefore, we get the optimum value of $Q$ by equating the right-hand side of equation (16) to zero. Again, the manufacturer's total cost per unit time is

$$
\begin{aligned}
T C_{m l} & =\frac{1}{t_{m}}\left(T C_{m}\right)=\frac{\left(A_{m}+A_{m}^{\prime}\right) D_{m} D_{c}^{\prime}}{\{x(1-z)+z\}(1-y) Q p_{m}} \\
& +\frac{D_{m} D_{c}^{\prime}}{\{x(1-z)+z\}(1-y) Q}\left\{\frac{\alpha(1-y) Q}{D_{m}}-\frac{1}{\beta}\left(e^{-\frac{\beta(1-y) Q}{D_{m}}-1}\right)\right\}+\frac{C_{m} D_{c}^{\prime}}{\{x(1-z)+z\}} \\
& +\frac{f_{c} D_{c}^{\prime 2}(1-z)}{D_{r}\{x(1-z)+z\}}+\frac{h_{m}}{2} \frac{D_{c}^{\prime}(1-y)(1-z)\left\{(1-z) p_{m}-D_{r}\right\} Q}{D_{m} D_{r}\{x(1-z)+z\}} \\
& +\frac{h_{m}^{\prime}}{2}\left\{z\left(\frac{2(1-z) p_{m}}{D_{r}}-1\right) \frac{(1-y) D_{c}^{\prime} Q}{D_{m}\{x(1-z)+z\}}+\frac{D_{c}^{\prime}\left(x D_{r}-D_{c}^{\prime}\right)(1-y)(1-z)^{2} p_{m} Q}{D_{m} D_{r}^{2}\{x(1-z)+z\}}\right. \\
& \left.+D_{c}^{\prime 2}\left(\frac{(1-z)}{D_{r}}-\frac{x(1-z)+z}{D_{c}^{\prime}}\right)^{2} \frac{(1-y) p_{m} Q}{\{x(1-z)+z\} D_{m}}\right\} .
\end{aligned}
$$


Differentiating the manufacturer's cost function $T C_{m l}$ twice with respect to $p_{m}$ we have:

$$
\begin{aligned}
\frac{\partial\left(T C_{m l}\right)}{\partial p_{m}} & =-\frac{\left(A_{m}+A_{m}^{\prime}\right) D_{m} D_{c}^{\prime}}{\{x(1-z)+z\}(1-y) Q p_{m}^{2}}+\frac{h_{m}}{2} \frac{D_{c}^{\prime}(1-y)(1-z)^{2} Q}{D_{m} D_{r}\{x(1-z)+z\}} \\
& +\frac{h_{m}^{\prime}}{2}\left\{\frac{2 z(1-z) D_{c}^{\prime}}{D_{r}\{x(1-z)+z\}}+\frac{D_{c}^{\prime}\left(x D_{r}-D_{c}^{\prime}\right)(1-z)^{2}}{D_{r}^{2}\{x(1-z)+z\}}\right. \\
& \left.+\left(\frac{(1-z)}{D_{r}}-\frac{x(1-z)+z}{D_{c}^{\prime}}\right)^{2} \frac{D_{c}^{\prime 2}}{x(1-z)+z}\right\} \frac{(1-y) Q}{D_{m}},
\end{aligned}
$$

and

$$
\frac{\partial^{2}\left(T C_{m l}\right)}{\partial p_{m}^{2}}=\frac{2\left(A_{m}+A_{m}^{\prime}\right) D_{m} D_{c}^{\prime}}{\{x(1-z)+z\}(1-y) Q p_{m}^{3}}>0
$$

This proves that the manufacturer's cost function is convex. We can get the optimum value of the manufacturer's decision variable by equating the right-hand side of equation (17) to zero. Next, the retailer's total cost per unit time is

$$
\begin{aligned}
T C_{r l} & =\frac{1}{T}\left(T C_{r}\right) \\
& =\frac{A_{r} D_{m} D_{c}}{(1-x)(1-y)(1-z) p_{m} Q}+\frac{C_{r} D_{c}}{1-x}+S_{m} D_{c}+h_{r} \frac{(1-y)(1-z)\left\{(1-x) D_{r}-D_{c}\right\} p_{m} Q}{2 D_{m} D_{r}} .
\end{aligned}
$$

The retailer's optimum total cost per unit time is obtained using optimum values of $Q$ and $p_{m}$.

\section{Backward induction}

In this method, we start the solution procedure from the follower (i.e. the retailer) and determine its optimal decisions on the lot size $Q$ of the supplier and the production rate of the manufacturer. Then, we derive the optimal costs of the supplier and the manufacturer depending on the decisions taken by the retailer. Differentiating the retailer's cost function per unit time with respect to $Q$ we have:

$$
\frac{\partial T C_{r l}}{\partial Q}=-\frac{A_{r} D_{m} D_{c}}{(1-x)(1-y)(1-z) p_{m} Q^{2}}+h_{r} \frac{(1-y)(1-z)\left\{(1-x) D_{r}-D_{c}\right\} p_{m}}{2 D_{m} D_{r}}
$$

and

$$
\frac{\partial^{2} T C_{r l}}{\partial Q^{2}}=\frac{2 A_{r} D_{m} D_{c}}{(1-x)(1-y)(1-z) p_{m} Q^{3}}>0 .
$$

Therefore, the retailer's cost function is convex with respect to $Q$. Again,

$$
\frac{\partial T C_{r l}}{\partial p_{m}}=-\frac{A_{r} D_{m} D_{c}}{(1-x)(1-y)(1-z) p_{m}^{2} Q}+h_{r} \frac{(1-y)(1-z)\left\{(1-x) D_{r}-D_{c}\right\} Q}{2 D_{m} D_{r}},
$$

and

$$
\frac{\partial^{2} T C_{r l}}{\partial p_{m}^{2}}=\frac{2 A_{r} D_{m} D_{c}}{(1-x)(1-y)(1-z) p_{m}^{3} Q}>0
$$

Therefore, it is proved that the retailer's cost function is convex with respect to the manufacturer's production rate.

The optimum values of $Q$ and pm can be obtained by equating the right-hand side of the equation (18) and (19) to zero and we can determine the optimum total cost of the supplier and the retailer by using these values. 


\section{Numerical example}

Example 1. We have proposed the following numerical example to illustrate the applicability of the proposed model. The values of the variables are taken as: $p_{s}=6, A_{s}=180, p_{s}^{\prime}=2, C_{s}=$ $0.5, h_{s}=2, A_{m}=300, D_{m}=60, D_{r}=48, D_{c}^{\prime}=9, x=0.2, y=0.06, z=0.1, \alpha=20, \beta=$ $0.02, C_{m}=0.7, h_{m}=4, h_{m}^{\prime}=3, f_{c}=5, A_{r}=150, A_{m}^{\prime}=100, S_{m}=40, C_{r}=0.8, h_{r}=$ $3, a=35, b=0.05, S_{r}=60$.

\begin{tabular}{|c|c|c|c|c|c|}
\hline$Q^{*}$ & $p_{m}^{*}$ & $T C_{s}$ & $T C_{m}$ & $T C_{r}$ & $T C$ \\
\hline \hline 110.56 & 56.51 & 615.08 & 878.22 & 1397.55 & 2890.85 \\
\hline
\end{tabular}

Table 1: Optimum results of Example 1

Again, using the above parameter values, we get different results for the backwards induction method, which are shown in Table 2.

\begin{tabular}{|c|c|c|c|c|c|}
\hline$Q^{*}$ & $p_{m}^{*}$ & $T C_{s}$ & $T C_{m}$ & $T C_{r}$ & $T C$ \\
\hline \hline 85.31 & 144 & 622.10 & 965.84 & 1381.28 & 2969.22 \\
\hline
\end{tabular}

Table 2: Optimum results for backwards induction method

We observe from Tables 1-2 that when the supplier and the manufacturer takes the decisions, then the costs of these two partners, as well as the cost of the total supply chain system are lower than those in the backwards induction method, i.e., this supply chain system performs better if the supplier and the manufacturer take the decisions.

\section{Sensitivity analysis}

Here we have discussed the changes in the optimal decision variables with the changes in different parameters involved in this model. We have used Example 1 for the values of the different parameters. In this model the retailer just follows the supplier and the manufacturer, he doesn't have any decision variable. So, we have studied the effect of changes in the parameters only on the supplier and the manufacturer's decision variables.

The effect of the parameters $y, D_{m}$, and $h_{s}$ on the optimal lot size $Q$ of the supplier and the total cost $T C_{s}$ of the supplier are depicted in Table 3.

\begin{tabular}{|c|c|c|c|}
\hline Changing parameter & Change in parameter & $Q^{*}$ & $T C_{s}^{*}$ \\
\hline \hline \multirow{3}{*}{$y$} & 0.06 & 110.56 & 615.08 \\
& 0.07 & 111.74 & 618.17 \\
& 0.08 & 112.96 & 621.32 \\
& 0.09 & 114.20 & 624.55 \\
\hline \multirow{3}{*}{$D_{m}$} & 55 & 105.85 & 572.30 \\
& 60 & 110.56 & 615.08 \\
& 65 & 115.07 & 657.50 \\
$h_{s}$ & 70 & 119.41 & 699.61 \\
\hline & 1.5 & 127.66 & 587.23 \\
& 2.0 & 110.56 & 615.08 \\
& 2.5 & 98.88 & 639.61 \\
& 3.0 & 90.27 & 661.79 \\
\hline
\end{tabular}

Table 3: Effect of parameters on the supplier's optimal solution 
Here we have studied the effect of the parameters $y, D_{m}, h_{m}$ and $k$ on the optimal production rate $p_{m}$ of the manufacturer and the total cost $T C_{m}$ of the manufacturer. The results are presented in Table 4.

\begin{tabular}{|c|c|c|c|}
\hline Changing parameter & Change in parameter & $P_{m}^{*}$ & $T C_{m}^{*}$ \\
\hline \hline \multirow{3}{*}{$y$} & 0.06 & 56.51 & 878.22 \\
& 0.07 & 57.12 & 879.38 \\
& 0.08 & 57.74 & 880.54 \\
$D_{m}$ & 0.09 & 58.37 & 881.71 \\
\hline & 55 & 51.80 & 868.30 \\
& 60 & 56.51 & 878.22 \\
$h_{m}$ & 65 & 61.22 & 886.62 \\
& 70 & 65.92 & 893.81 \\
\hline \multirow{3}{*}{$h_{m}^{\prime}$} & 4 & 56.51 & 878.22 \\
& 5 & 51.54 & 878.50 \\
& 6 & 47.69 & 876.71 \\
& 7 & 44.59 & 873.31 \\
\hline & 3 & 58.40 & 872.4 \\
& 4 & 56.51 & 878.22 \\
& 5 & 54.78 & 883.70 \\
& 3 & 53.21 & 888.94 \\
\hline
\end{tabular}

Table 4: Effect of parameters on the manufacturer's optimal solution

\subsection{Observations}

From the tables, it is observed that:

- The order lot-size of the supplier and his total cost both increase with the increase of the parameters y and the demand rate of the manufacturer to the supplier $\left(D_{m}\right)$. This result is quite realistic as if the amount of the defective raw material observed by the supplier increases, then the supplier tries to increase the order lot-size to get rid of the shortage. On the other hand, if the demand rate of the manufacturer to the supplier increases, then the supplier also has to order rawer materials for the smooth and efficient supply of raw material to the manufacturer. The increases in the total cost of the supplier for both the cases is obvious.

- If the holding cost of the supplier increases, then the supplier procures a lower quantity of raw materials and the total cost of the supplier increases in this case.

- With the increase in the parameter y the production rate of the manufacturer increases. This result is desirable because from the equation (1) it is observed that the manufacturer's production time decreases with the increase in y. So, to build an adequate inventory level, it is wise for the manufacturer to increase his production rate. Therefore, the total cost of the manufacturer increases.

- As the rate of procurement of raw material of the manufacturer increases, the production rate of the manufacturer and his total cost both increases.

- The manufacturer decreases his production rate as the holding cost for both the perfect and defective products $\left(h_{m}\right.$ and $\left.h_{m}^{\prime}\right)$ increase. With the increase in $h^{\prime} m$, the manufacturer's total cost increases, but it decreases with the increase in $\mathrm{hm}$. 


\section{Conclusion}

This article presents a three-echelon supply chain model consisting of a single supplier, single manufacturer and a single retailer. This research work includes some practical implications likeinspection error and learning effect of the employees. Besides, the manufacturer maintains an integration with the retailer by offering him a return contract. Moreover, if the manufacturer sells the defective products to the customers, it may impact badly on the company's brand reputation. Keeping in mind this fact, the manufacturer reworks all the defective products and sells these directly to the customers as the refurbished products at a reduced price (as these products may still fail to work properly in their useful life).

We have derived the cost functions of each of the supply chain players and studied the effect of the different parameters on their optimum decision variables. We have solved this model using leader-follower relationship approach and compared the results with backwards induction method. This model can be extended in various ways. Most importantly, we can extend this model by adding one or more supply chain players. Besides, we can consider the customers' demand for the product to the retailer as fuzzy, stochastic, stock dependent etc.

\section{References}

[1] Astanjin, M. B. and Sajadieh, M. S. (2017). Integrated production-inventory model with pricedependent demand, imperfect quality and investment in quality and inspection. AUT Journal of Modeling and Simulation, 49(1), 43-56. doi: 10.22060/MISCJ.2016.835

[2] Cheikhrouhou, N., Sarkar, B., Ganguly, B., Iqbal, A. I., Batista, R. and Youang. H. (2018). Optimization of sample size and order size in an inventory model with quality inspection and return of defective items. Annals of Operations Research, 271(2), 445-467. doi: 10.1007/s10479017-2511-6

[3] Defee, C. C. (2007). Supply chain leadership. PhD dissertation. Knoxville: University of Tennessee. https://trace.tennessee.edu/utk_graddiss/14

[4] Jauhari, W. A., Sulistyanto, R. and Laksono, P. W. (2018). Coordinating a two-level supply chain with defective items, inspection errors and price-sensitive demand. Songklanakarin Journal of Science and Technology, 40(1), 135-145. doi: 10.14456/sjst-psu.2018.2

[5] Jauhari, W. A., Widianto, I. P. and Rosyidi, C. N. (2017). A supply chain inventory model for vendor-buyer system with defective items and imperfect inspection process. International Journal of Mathematics in Operational Research, 11(4), 450-469. doi: 10.1504/IJMOR.2017.087740

[6] Khanna, A., Kishore, A. and Jaggi. C. K. (2017) Inventory modeling for imperfect production process with inspection errors, sales return and imperfect rework process. International Journal of Mathematical, Engineering and Management Sciences, 2(4), 242-258. doi: 10.33889/IJMEMS.2017.2.4-019

[7] Khouja, M. and Mehrez, A. (1994). Economic production lot size model with variable production rate and imperfect quality. Journal of the Operational Research Society, 45(2), 1405-1417. doi: 10.1057 /jors.1994.217

[8] Maddah, B., Moussawi, L. and Jaber, M. Y. (2010). Lot sizing with a Markov production process and imperfect items scrapped. International Journal of Production Economics, 124(2), 340-347. doi: $10.1016 /$ j.ijpe.2009.11.029

[9] Maity, A. K., Maity, K., Mondal, S. K. and Maiti M. (2009). A production-recycling-inventory model with learning effect. Optimization and Engineering, 10(3), 427-438. doi: 10.1007/s11081009-9084-4

[10] Noori-daryan M. and Taleizadeh A. A. (2019). Optimizing pricing and ordering strategies in a three-level supply chain under return policy. Journal of Industrial Engineering International, 15(1), 73-80. doi: 10.1007/s40092-018-0262-x

[11] Parvini, M., Atashi, A., Husseini, S. M. M. and Esfahanipour, A. (2014). A two-echelon inventory model with product returns considering demands dependent return rates. International Journal of Advanced Manufacturing Technology, 72(1-4), 107-118. doi: 10.1007/s00170-014-5645-6 
[12] Priyan, S. and Manivannan, P. (2017). Optimal inventory modeling of supply chain system involving quality inspection errors and fuzzy defective rate. OPSEARCH, 54(1), 21-43. doi: $10.1007 / \mathrm{s} 12597-016-0267-4$

[13] Rosenblatt, M. J. and Lee, H. L. (1986). Economic production cycles with imperfect production processes. IIE Transactions, 18(1), 48-55. doi: 10.1080/07408178608975329

[14] Sana, S. S. (2010). An economic production lot size model in an imperfect production system. European Journal of Operational Research, 201(1), 158-170. doi: 10.1016/j.ejor.2009.02.027

[15] Sharma, M. K. and Bansal, K. K. (2017). Inventory model for non-instantaneous decaying items with learning effect under partial backlogging and inflation. Global Journal of Pure and Applied Mathematics, 13(6), 1999-2008. https://www.ripublication.com/gjpam17/gjpamv13n6_44.pdf

[16] Singh, N., Vaish, B. and Singh, S. (2012). An economic production lot-size (EPLS) model with rework and flexibility under allowable shortages. International Journal of Procurement Management, 5(1), 104-122. doi: 10.1504/IJPM.2012.044156

[17] Singh, S. R. and Gupta, V. (2016). Vendor-buyer model with error in quality inspection and selling price dependent demand rate under the effect of volume agility. International Journal of Operations and Quantitative Management, 22(4), 357-371. http://www.ijoqm.org/v22no4.asp\#

[18] Zhao, Q. and Yang, J. (2007). Optimal pricing and return policy for enterprise under supply chain management. International Journal of Management and Enterprise Development, 4(2), 218-233. doi: 10.1504/IJMED.2007.011793 